\title{
Genetic Predisposition to Myeloproliferative Neoplasms: Another Piece of the Puzzle
}

\author{
Maya Koren-Michowitz \\ Department of Hematology, Assaf Harofeh Medical Center, Zeriffin, Israel; Sackler Faculty of Medicine, \\ Tel Aviv University, Tel Aviv, Israel
}

The myeloproliferative neoplasms (MPN) are clonal hematopoietic disorders characterized by the overproduction of mature myeloid cells and a prolonged disease course. The WHO classification has recently characterized 7 different MPN entities, the more common ones being $B C R-A B L 1$-positive chronic myeloid leukemia, polycythemia vera, essential thrombocythemia, and primary myelofibrosis [1]. Three major phenotypic drivers underlie most cases of $B C R-A B L$-negative MPN, including somatic mutations in JAK2, most commonly the JAK2V617F mutation, CALR, and MPL.

MPN occur sporadically in most cases. However, familial clustering of $B C R-A B L$-negative MPN has been reported, with a 5- to 7-fold increased MPN risk among first-degree relatives of MPN patients [2]. Research into the mechanisms underlying predisposition to MPN have discovered candidate genetic variants, which segregate into 1 of the following categories: rare genetic variants, found in a small number of families with a high penetrance for disease, or common variants that are prevalent in the population and result in a small increased risk to

\section{KARGER}

() 2018 S. Karger AG, Basel

E-Mail karger@karger.com

www.karger.com/aha develop MPN. Two models through which germline variation may increase MPN incidence were suggested [3]: DNA hypermutability, in which certain genetic variants/ haplotypes are genetically unstable and predispose to an increased somatic mutation rate, and permissive genetic background, where acquired mutations could have survival advantage in a certain milieu.

In the last issue of Acta Haematologica, Andersen et al. [4] reported on the prevalence of MPN in twin pairs from the Danish Twin Registry. In 140 identified twin pairs with a diagnosis of MPN and known zygosity status, 3 monozygotic twin pairs had a concordant MPN diagnosis, i.e., MPN was diagnosed in both twins, and all dizygotic twin pairs had a discordant MPN diagnosis. This translated into a significant difference in the concordance rate for monozygotic compared to dizygotic twins of $15 \%$ (95\% CI, 0.059; 0.31) and 0\% (95\% CI, 0; 0.035), respectively $(p=0.016)$. The mean age at the time of diagnosis was 64.5 years for the discordant twins and 75.4 years for the concordant twins, similar to the age at diagnosis in the general population, in which the incidence of MPN in- 
creases with age. While derived from a large twin registry database including more than 86,000 Danish twin pairs, some limitations of this paper are the lack of data on specific MPN diagnoses and the very limited number of MPN twin cases included in the final analysis.
This paper provides additional support of the theory that MPN develops over many years in a permissive germline genetic background.

\section{References}

1 Arber DA, Orazi A, Hasserjian R, Thiele J, Borowitz MJ, Le Beau MM, et al: The 2016 revision to the World Health Organization classification of myeloid neoplasms and acute leukemia. Blood 2016;127:23912405.

2 Landgren O, Goldin LR, Kristinsson SY, Helgadottir EA, Samuelsson J, Bjorkholm M: Increased risks of polycythemia vera, essential thrombocythemia, and myelofibrosis among
24,577 first-degree relatives of 11,039 patients with myeloproliferative neoplasms in Sweden. Blood 2008;112:2199-2204.

3 Nangalia J, Green AR: Myeloproliferative neoplasms: from origins to outcomes. Blood 2017;130:2475-2483.

4 Andersen MA, Bjerrum OW, Ranjan A, Skov V, Kruse T, Thomassen M, et al: Myeloproliferative neoplasms in Danish twins. Acta Haematol 2018;139:195-198. 